\title{
Visualizing the efficacy of vaccination in different Indian states: a comparative account with other countries
}

\author{
Ruchira Mukherjee $^{1} \cdot$ Sabnam Islam ${ }^{1} \cdot$ Aparna Mukhopadhyay ${ }^{1}$ (I)
}

Received: 19 October 2021/Accepted: 30 January 2022/Published online: 1 March 2022

(C) The Author(s), under exclusive licence to Indian Virological Society 2022

\begin{abstract}
Efficacy of the vaccination program for COVID19 pandemic caused by SARS-CoV-2 (Severe Acute Respiratory Syndrome-CoronaVirus-2) was analyzed. The data for number of cases and vaccination, obtained from government websites from 1st January, 2020 to 10th October, 2021 for India, USA, United Kingdom, Italy, South Africa and states West Bengal, Delhi, Maharashtra, Kerala and Tamil Nadu. Modified Poisson prediction models were developed using SPSS to predict the number of cases with and without vaccination as predictor to catalogue the efficacy of vaccination. In the prediction model where vaccination was used as a predictor, the downward trend of predicted value matched with actual value, falling within the $95 \%$ confidence interval. However, individual peaks of waves were not observed clearly for the predicted values. Vaccination within the population was observed to be very critical in controlling the pandemic progression with all countries showing decrease in daily case counts as more people in the population got vaccinated. In India, owing to the huge population, more vaccination is needed for the predicted cases to fall lower.
\end{abstract}

Keywords Vaccination - SARS-CoV-2 - Negative binomial regression $\cdot$ Lockdown

Aparna Mukhopadhyay

aparna.dbs@presiuniv.ac.in

1 Department of Life Sciences, Presidency University, Kolkata, India

\section{Introduction}

The corona virus disease or COVID-19 is so called, based on its causative agent, SARS-CoV-2 (Severe Acute Respiratory Syndrome Corona Virus 2), first reported during December, 2019, from Wuhan, China. The virus spread throughout the world culminating into pandemic, acculturating individuals to the 'new normal'. Transmitted via air, apart from the respiratory tract, the virus affects other organs too causing gastrointestinal, hepatic and neurological disorders [43, 55]. While the common symptoms include fever, cough, fatigue [52, 55], severe cases culminate in pneumonia, acute respiratory distress syndrome (ARDS) $[32,43]$ which may subsequently conduce to death $[52,55]$.

As of 10th October, 2021 the worldwide tracking of COVID-19 infections reported 238,732,756 confirmed cases including 215,894,598 recovered and 4,869,929 dead [14]. The course of disease progression is different in almost all countries. Multitudinous factors explain this variability; like ethnicity, biogeography, environmental niche, co-morbidities, genetic factors, socio-economic status [2, 30, 34], social differences [33], temperature [37] and climate [45].

In the context of social differences and ethnicity, evaluation of hospitalized patients from 14 different States in USA observed $45 \%$ patients to be Caucasian, 33\%AfricanAmerican, $8.1 \%$ Hispanic, 5.5\% Asian, less than 1\% American Indian/ Alaskan native and $7.9 \%$ patients belonged from unknown race(s) [30]. In the context of temperature and climate, a Brazilian study defined the association between the number of COVID-19 cases and temperature to be negative with an approximate increase in 6.4 cases per day accompanying an average $1^{\circ} \mathrm{F}$ fall in temperature [45]. Besides, approximately 56.01 cases were 
seen to increase per day with 1 inch increase in daily precipitation [45]. These studies reiterate differences in the trend of COVID-19 spread and pattern; which besides differing among countries, also differs at various locations within a country [4].

In an effort to control the diverse trends in the pandemic transmission, stringent implementation of lockdown and social distancing was adopted as the common base by policy makers all around the world [38]. It controlled the explosion of cases causing the first wave to subside but also markedly hampered the daily lives of global population [46]. Subsequent relaxation in the government-imposed restrictions for economic purposes allowed restricted resumption of daily activities but also inflated case numbers causing subsequent waves of infection [18] and further disruption in daily life.

Social constraints due to the unremitting pandemic have adversely affected mental well-being [56]. Fear of the pandemic is tremendous among people [42]. Recurrent infectious waves increase the urgency of obtaining solutions in terms of treatment methodology, specific medication and vaccination. While specific medicine and/or uniform treatment methodology against the disease is lacking [44], many reports suggest vaccination as the only solution [51, 23, 27].

Vaccines have been developed targeting the spike protein and genome of the virus [19]. Vaccination program started from the month of December'20 or January'21 in almost all countries [36]. Visualization of the situation after vaccination is essential to assess its efficacy in bringing down the COVID-19 cases. A prediction model can help visualize fall in daily cases, subsequently marking the end for COVID-19, lockdown and social-distancing, indicating resumption of normal life.

Earlier prediction models developed for India [22], USA $[57,58]$ did not take into account the vaccination. Economic demands necessitate lockdown relaxation, so vaccination is the only way to overcome the pandemic. In this study, the number of people vaccinated has been focused upon to visualize how the vaccination program has affected the pandemic spread. This study aimed to compare and predict the trend of COVID-19 in different countries and Indian states in context of vaccination.

\section{Material and methods}

\section{Details of study selection}

Uniform treatment criteria for COVID-19 cases is unavailable making vaccination the key to handling the pandemic. This makes the study of vaccination efficacy and its progress essential for monitoring of the pandemic.
Predictions based on vaccination can not only indicate the end of the pandemic but also shed light on how well the pandemic is handled in different locations.

Details on the countries and states selected, their basis for selection and websites from where data was acquired are provided in subsequent sections. Since data was collected from publicly available information, no ethical clearance was necessary.

\section{Countries and Indian states selected}

The countries and states, most severely affected by the SARS-CoV-2 were considered in the study. USA had been the worst affected country in America [9] while Italy and UK had been worst affected in Europe [26, 10]. To encompass ethnic differences, Africa was also incorporated in the study [47, 53]. India came second when total cases were considered [5]. Among Indian states, first patient of COVID-19 was identified in Kerala $[24,1]$ gradually spreading to other states but the worst situation had been observed in states having high international migrationMaharashtra, Tamil Nadu, Delhi and West Bengal [41]. Hence these regions were considered for the study.

\section{Data acquisition}

Data for USA, United Kingdom, Italy, South Africa was collected from ourworldindata.org [11] while data for India, Maharashtra, Tamil Nadu, Delhi and West Bengal was collected from covid19.org [12]. The variables considered were daily count of cases and vaccination. Dataset included dates and corresponding daily new cases, cumulative confirmed cases spanning from 1st January, 2020 until 10th October, 2021 besides the total count of vaccinated people till 10th October, 2021. These parameters were recorded on a daily basis within the time span specified. As specific parameters were taken, no further normalization, screening or removal of unnecessary objects were required.

Dataset was arranged in MS Excel and all analysis was done using SPSS.

\section{Poisson regression}

Poisson regression is most commonly used to model count data. Poisson regression assumes equi-dispersion in data. If this criterion is not met, the data must be adjusted using dispersion parameter. Then, this generalized form of Poisson regression is known as negative binomial regression, which can thus be availed for prediction. 
Table 1 Deviance and Omnibus Test

\begin{tabular}{|c|c|c|c|c|c|c|}
\hline \multirow[t]{3}{*}{ State/Country } & \multirow{2}{*}{\multicolumn{2}{|c|}{$\frac{\text { Model Fit }}{\text { Deviance Value/df }}$}} & \multicolumn{4}{|l|}{ Omnibus test } \\
\hline & & & \multicolumn{2}{|l|}{ Chi-square } & \multicolumn{2}{|l|}{ Sig } \\
\hline & Without vaccination & With vaccination & Without vaccination & With vaccination & Without vaccination & With vaccination \\
\hline India & 1.272 & 1.256 & 1369.516 & 1462.206 & 0 & 0 \\
\hline USA & 1.241 & 1.221 & 76.591 & 240.576 & 0 & 0 \\
\hline UK & 1.231 & 1.215 & 244.236 & 361.609 & 0 & 0 \\
\hline Italy & 1.253 & 1.224 & 68.353 & 282.743 & 0 & 0 \\
\hline South Africa & 1.257 & 1.26 & 87.755 & 95.96 & 0 & 0 \\
\hline West Bengal & 1.241 & 1.215 & 79.679 & 235.816 & 0 & 0 \\
\hline Delhi & 1.31 & 1.242 & 19.932 & 344.264 & 0 & 0 \\
\hline Kerala & 1.214 & 1.192 & 463.132 & 622.617 & 0 & 0 \\
\hline Maharashtra & 1.192 & 1.157 & 102.517 & 304.581 & 0 & 0 \\
\hline Tamil Nadu & 1.231 & 1.214 & 93.788 & 194.485 & 0 & 0 \\
\hline
\end{tabular}

Table 2 Parameter Estimates for India

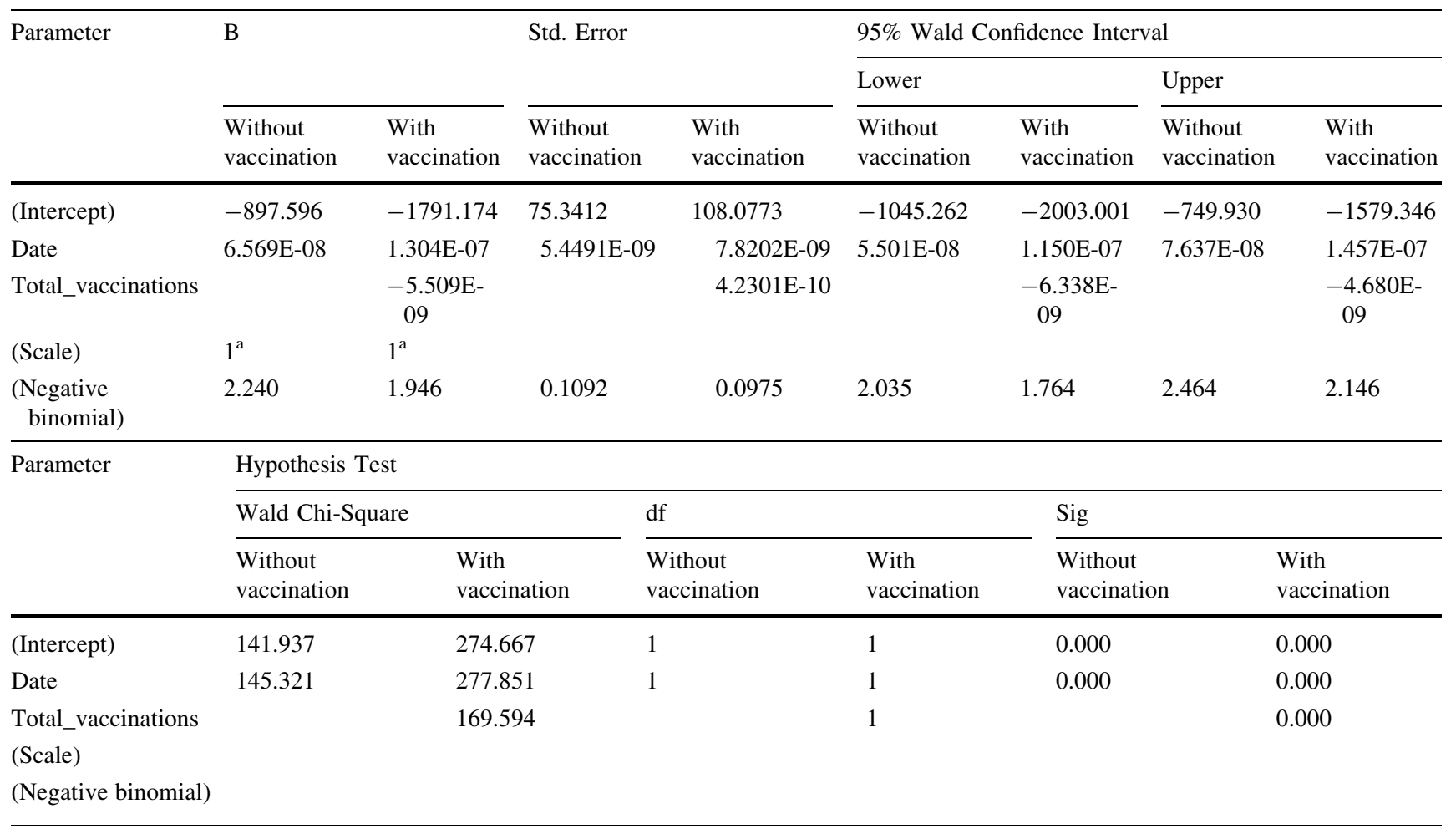

Dependent Variable: Daily_cases

Model: (Intercept), Date (Without vaccination)

Model: (Intercept), Date, Total_vaccinations (With vaccination)

${ }^{\mathrm{a}}$ Fixed at the displayed value 
Table 3 Parameter Estimates for USA

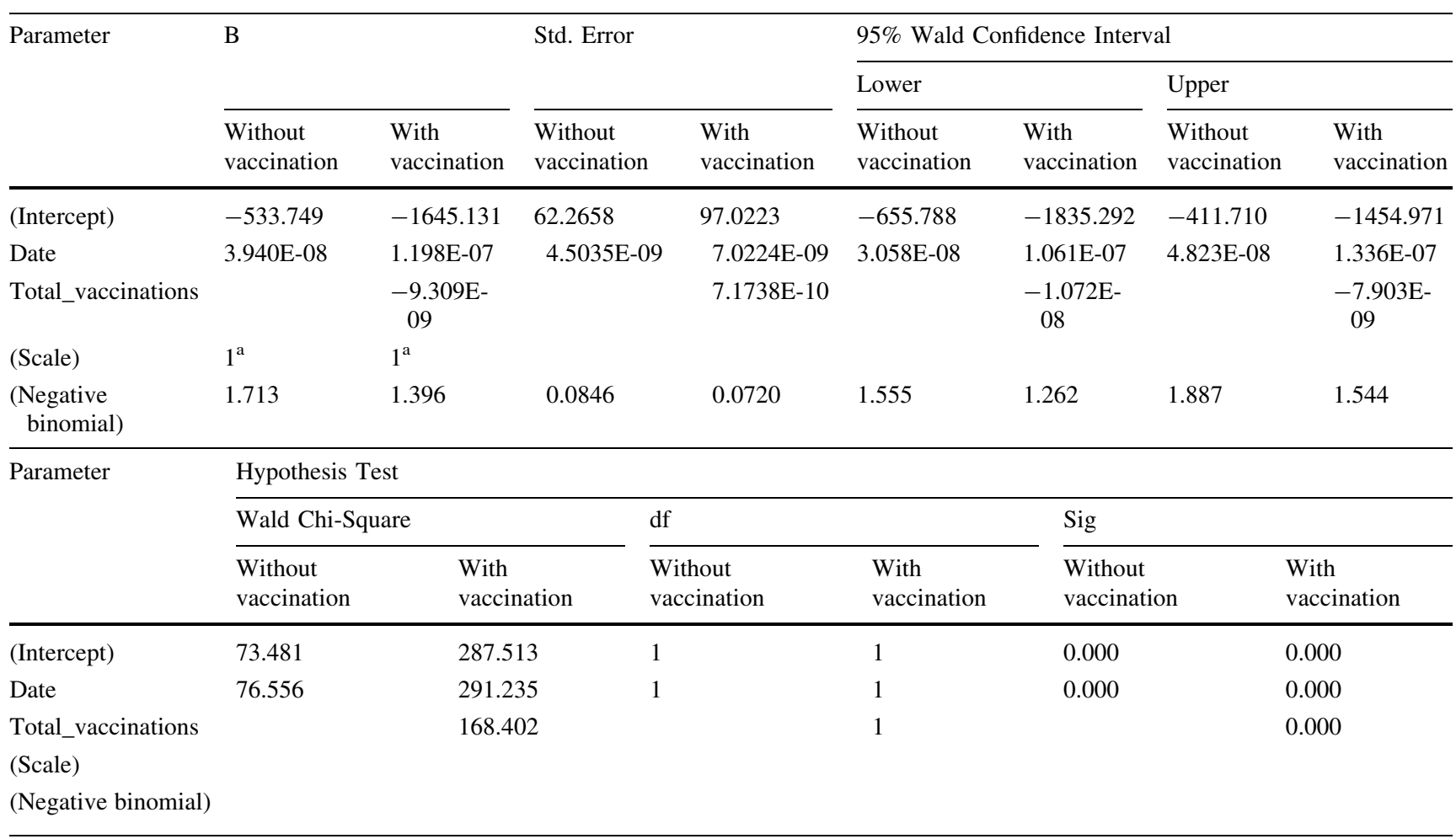

Dependent Variable: Daily_cases

Model: (Intercept), Date (Without vaccination)

Model: (Intercept), Date, Total_vaccinations (With vaccination)

${ }^{a}$ Fixed at the displayed value

\section{Model fit}

To estimate equi-dispersion in the data, the deviance value divided by degree of freedom (df) is estimated. The deviance is "twice the difference between the maximum achievable log-likelihood and the log-likelihood of the fitted model". [Deviance value/df] when equal to 1 is indicative of equi-dispersion, less than 1 indicates underdispersion and greater than 1 indicates over-dispersion. For the latter cases, the dispersion parameter can either be set to default or estimated under negative binomial log function. Preference to the model developed with either default or estimated dispersion parameter is based on whichever has lower AIC (Akaike Information Criterion) or BIC (Bayesian Information Criterion) values.

\section{Omnibus test}

It assesses whether all the predictors collectively improve the model prediction over intercept-only model (i.e., with no independent variables or predictors). A level of significance or p-value less than 0.05 indicate statistically significant model.

Initial evaluations showed over-dispersion in data, so the data was adjusted using the dispersion parameter by utilizing the "estimate value" function available in SPSS. The models where the dispersion parameter was calculated based on the data (and not default value of dispersion parameter used), showed lower AIC and BIC values. This held true for all selected locations. Thus, negative binomial regression models with estimated dispersion parameter were preferred and henceforth represented.

\section{Results}

For each selected location, two negative binomial regression models were developed- one with vaccination as the predictor, the other without vaccination as a predictor so as to catalogue the effectiveness of vaccination in altering the trend of the pandemic. 
Table 4 Parameter Estimates for UK

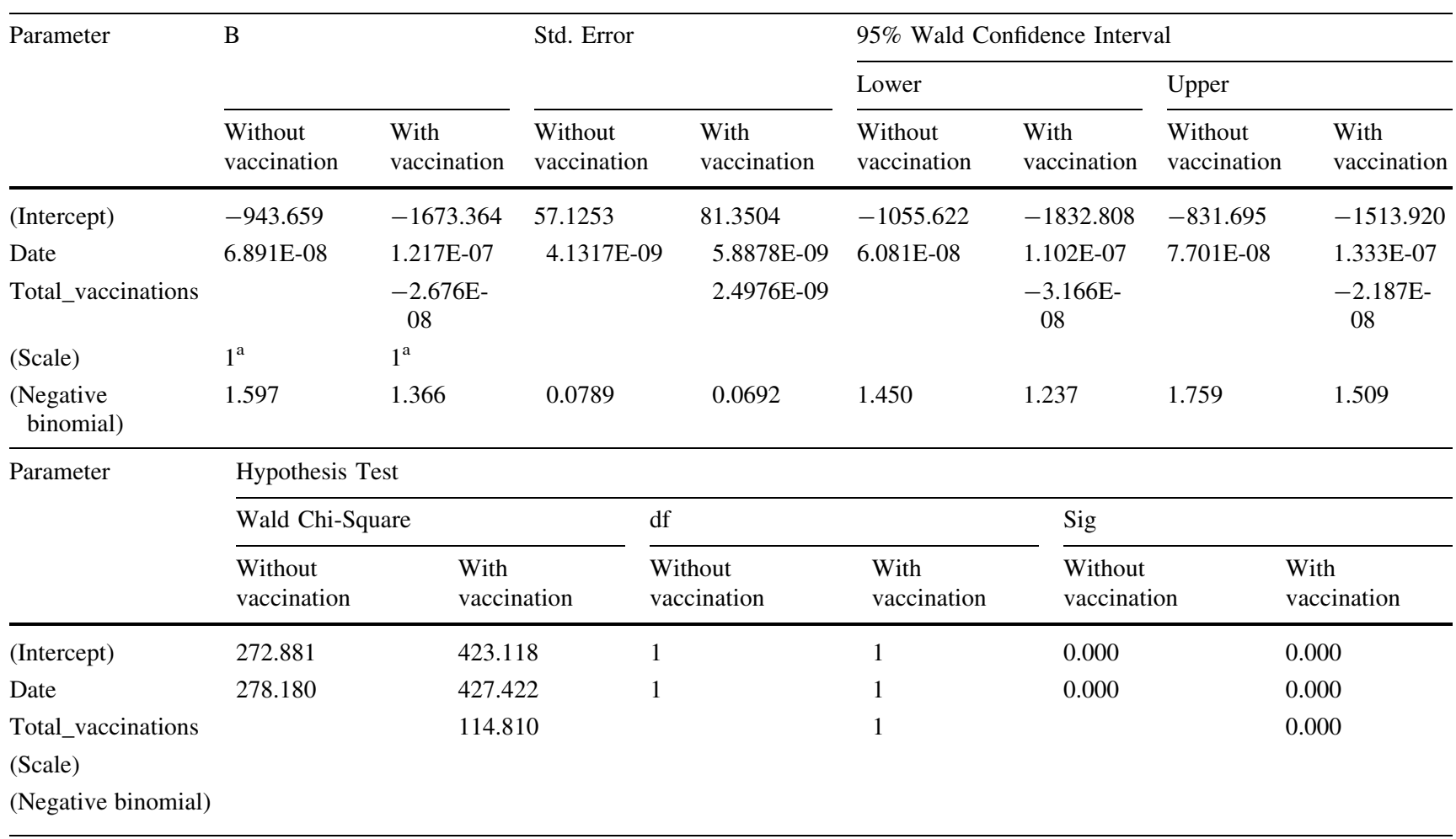

Dependent Variable: Daily_cases

Model: (Intercept), Date (Without vaccination)

Model: (Intercept), Date, Total_vaccinations (With vaccination)

${ }^{a}$ Fixed at the displayed value

\section{Prediction of daily cases in different countries and states}

Dispersion, AIC and BIC value for each individual prediction model for each location has been tabulated (Table 1). All the generated prediction models were found to be statistically significant $(p<0.05)$ as indicated by Omnibus test (Table1).

The models coefficients have been tabulated in Tables 2 , $3,4,5,6,7,8,9,10,11$. All the predictors were significant for every model $(\mathrm{p}<0.05)$; this reinforces the Omnibus test results (Tables 2, 3, 4, 5, 6, 7, 8, 9, 10, 11).

\section{Daily cases versus predicted value of mean of response by date for countries}

India (Fig. 1a) saw the peak of first wave in AugustSeptember 2020 which was followed by a gradual decline in counts reaching a minimum in February-March 2021. However, a more severe second wave peaked in May, 2021 (Fig. 1a). In the model without vaccination, the predicted cases show no inclination to decrease from the upward trend (Fig. 1a.1) but when vaccination is used as a predictor, although the predicted model did not conform to the initial dip after the first wave, the best fitting predicted curve did conform to the current downward trend (Fig. 1a.2).

United States' data analysis showed the first wave peaking in April'20, a second wave in July'20, a more severe third wave in January'21 and since the onset of vaccination, a smaller fourth wave in April'21(Fig. 1b). Same as in the previous case, the predictive model without vaccination as an independent variable, the upward rising cases did not decrease (Fig. 1b.1). As per the model generated with vaccination, the predicted curve for USA is initially seen to reach towards $\mathrm{x}$-axis indicating control in COVID-19 cases (Fig. 1b.2) but in conformation to the ongoing infection wave, it turned upwards again. Similar observations were found for United Kingdom (Fig. 1c); the surge in number of predicted cases corresponding to the current infection wave (Fig. 1c.2) exceeds that of the previous peaks, which was not observed for USA. 
Table 5 Parameter Estimates for Italy

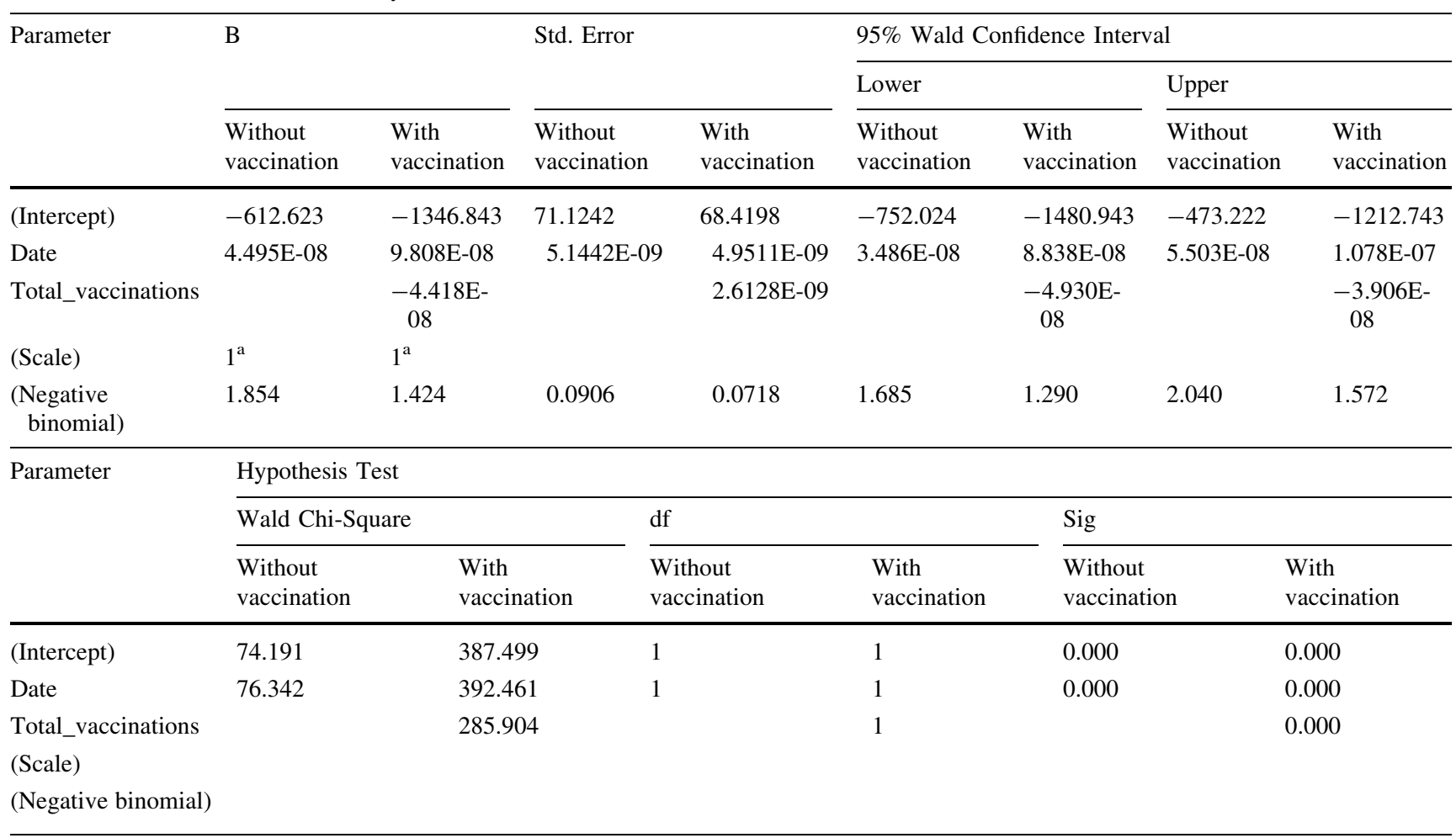

Dependent Variable: Daily_cases

Model: (Intercept), Date (Without vaccination)

Model: (Intercept), Date, Total_vaccinations (With vaccination)

${ }^{a}$ Fixed at the displayed value

In case of Italy (Fig. 1d), the first wave arrived at its peak during March'20. However, due to relaxation of lockdown a more severe second wave set in and peaked in November'20. A third wave peaked in March'21, though it was relatively smaller, probably due to the onset of vaccination. As in the previous cases, the model without vaccination as a predictor did not show decrease in case counts (Fig. 1d.1). But for the model involving vaccination, although the predicted peak did not correspond the actual case peak, followed a downward trend from the month of March'21 (Fig. 1d.2). Similar observations were recorded for South Africa (Fig. 1e) although the infections peaked at a later time compared to Italy.

\section{Daily cases versus value of predicted value of mean of response by date for Indian states}

West Bengal (Fig. 2a) witnessed the first wave to peak in November'20, followed by a gradual decline, reaching minimum in February-March'21. However, a more severe second wave commenced, peaking during May'21 conforming to the Indian scenario as a whole. While the predicted curve without vaccination showed no decline (Fig. 2a.1), as opposed to the predicted curve with vaccination (Fig. 2a.2) indicating vaccination to be effective in controlling the pandemic spread.

In case of Delhi (Fig. 2b), the first wave of infection had three peaks- in the month of June'20, September'20 and November'20. A more severe second wave was observed between February'21 and April'21. Both the predicted curves- with vaccination (Fig. 2b.1) and without vaccination (Fig. 2b.2) differ from each other, when vaccination is included as a predictor, the predicted daily cases fall conforming to the actual scenario.

Kerala data analysis showed (Fig. 2c) the first wave to peak in October'20 and a more severe second wave peaking in May'21. Without vaccination, the predicted cases don't show any decrease (Fig. 2c.1) but with vaccination as a predictor, the model predicts decline in cases (Fig. 2c.2).

Maharashtra saw (Fig. 2d) the first wave reaching its peak in September'20 and a more severe second wave 
Table 6 Parameter Estimates for South Africa

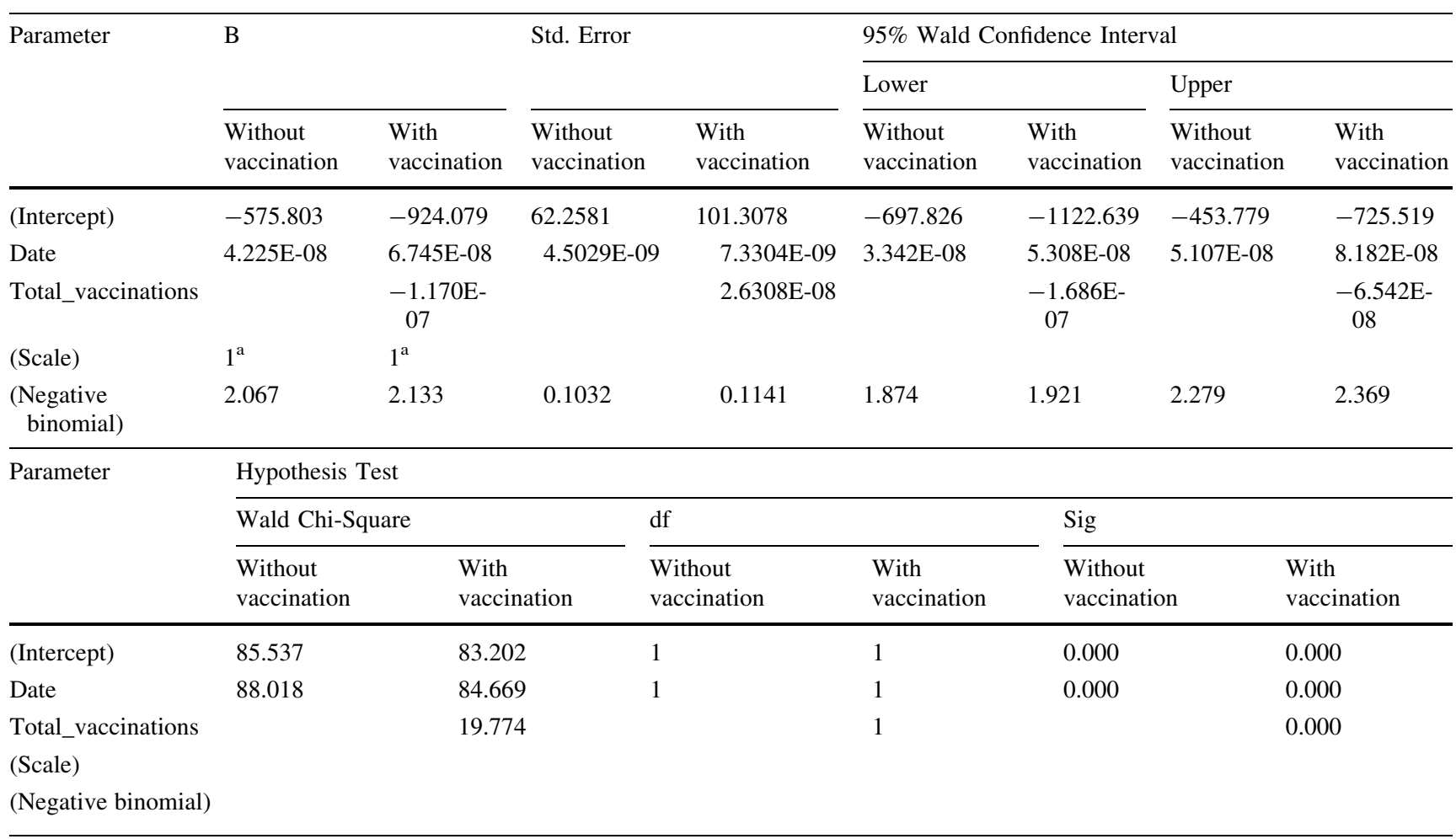

Dependent Variable: Daily_cases

Model: (Intercept), Date (Without vaccination)

Model: (Intercept), Date, Total_vaccinations (With vaccination)

${ }^{a}$ Fixed at the displayed value

peaking in May'21. Vaccination as a predictor (Fig. 2d.2) altered the predicted curve without vaccination (Fig. 2d.1) to a great extent. The downward trend obtained signified the efficacy of vaccination in Maharashtra.

Tamil Nadu (Fig. 2e) saw the first wave from April 2020 to January2021. The more severe second wave peaked in June'21. Similar to the observations in case of West Bengal, Delhi, Kerala and Maharashtra, both the predicted curves with and without vaccination as a predictor (Fig. 2e.2 and e.1, respectively) differed from each other, with the prior showing inclination towards the $\mathrm{x}$-axis.

The estimated curves with vaccination shows higher requirements of vaccination for all States (excluding Delhi) for controlling the pandemic.

For the models where vaccination is used as a predictor, the actual number of cases falls within the $95 \%$ confidence interval (CI) during the latter part simultaneous to ongoing vaccination program for maximum countries (Fig. 3) and Indian States (Fig. 4).

Proportion of people vaccinated in the selected countries and Indian States has been graphically represented in
Fig. 5. Highest proportion of the population has been vaccinated in United Kingdom while the lowest proportion to receive at least one dose of vaccine was seen in South Africa. Among the Indian States, the highest proportion of people to receive at least one dose of vaccine by 10th October, 2021 was Kerala while the lowest numbers were recorded in West Bengal.

\section{Discussion}

India, USA, Italy, UK, South Africa and within India, Maharashtra, Delhi, Tamil Nadu, Kerala, West Bengal constitute populations belonging to varying ethnicity, biogeography and climate. This justified generation of individual prediction model for each location. The estimated models portrayed that the trend of rising cases change once vaccination was implemented.

Vaccination engendered decrease in daily cases for India mid-May, 2021 onwards before which the Indian scenario was very severe with continual inflation in case counts. The 
Table 7 Parameter Estimates for West Bengal

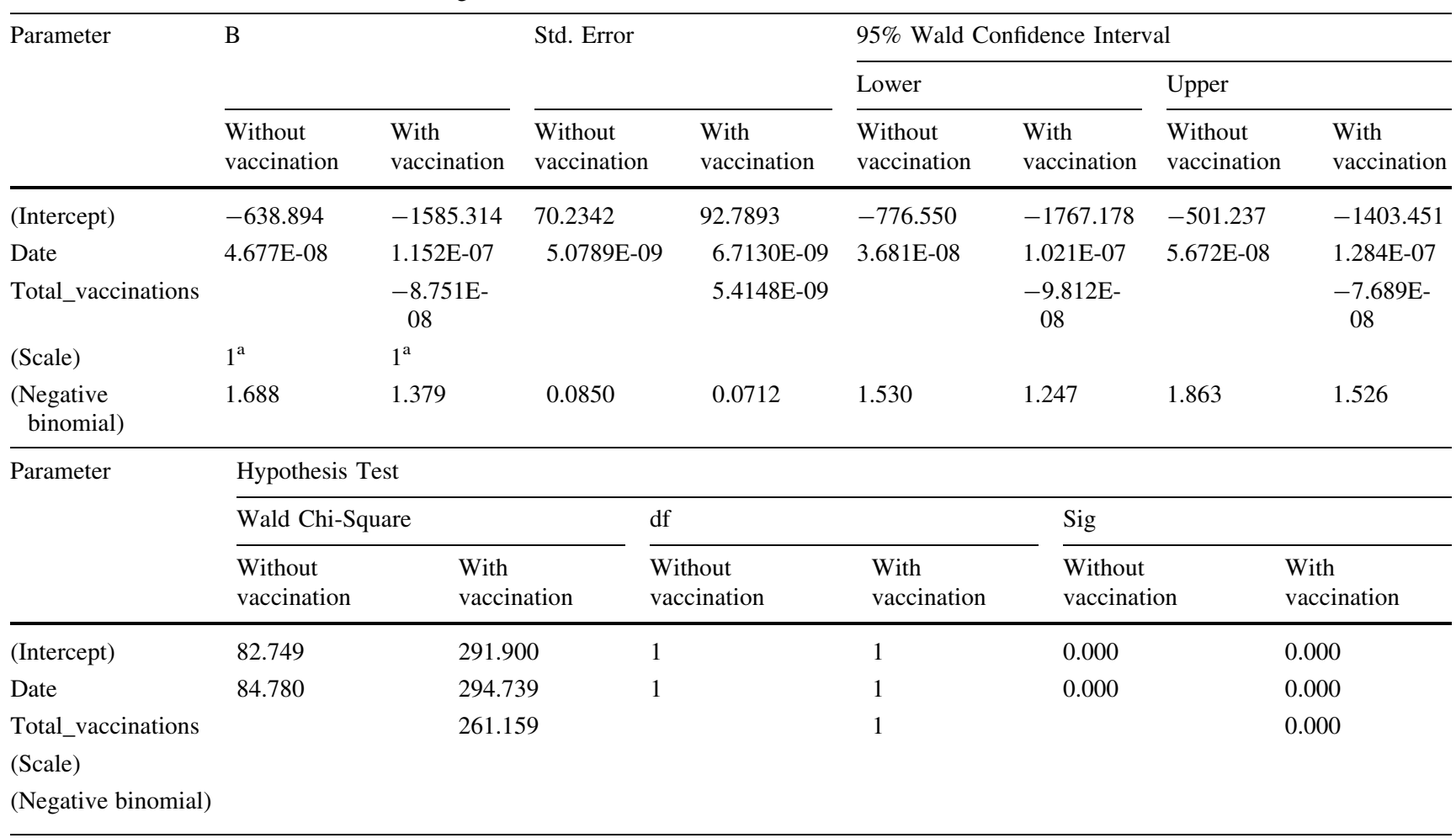

Dependent Variable: Daily_cases

Model: (Intercept), Date (Without vaccination)

Model: (Intercept), Date, Total_vaccinations (With vaccination)

${ }^{a}$ Fixed at the displayed value

first and second waves happened within the space of five months. Effectiveness of social distancing, mask usage and lockdown most probably controlled the first wave. Most importantly, ending of first wave at mid-week of February was likely a result of experience gained from the initial months by the medical experts in treating COVID- 19 .

However, case counts surged on 15 April, 2021 with number of daily cases being 0.2 million. Speculative reasons for the surge firstly include the double mutant variants of SARS-CoV-2 (B.1.617 lineage) identified in Maharashtra, West Bengal and Delhi in April, 2021 [21], which were reportedly more infectious than the first wild type variants of early 2020 [6]. Besides, UK and South African variants detected in Kerala in April'21 [50] were reportedly more transmissible than the original [40], thus bolstering case counts.

Secondly, mass gathering in Kumbhmela [31], festivals like Bihu [13], national farmers' movement [28] and election [28] in several states spawned negligent behavior in the population. Thirdly, natural disasters like cyclone 'Yaas' in West Bengal [16], 'Tauktae' in Delhi,
Maharashtra, Kerala and Tamil Nadu [17] that hit the states amid a devastating second wave of COVID-19 led to worsening in handling the spread of virus.

The second wave was again met with lockdown although dates and restriction varied across different states. Delhi went under lockdown from 19th April 2021 [3]. Maharashtra imposed weekend lockdown from 4th April, 2021[35]. Lockdown in Tamil Nadu began from 10th May, 2021 [8]. West Bengal imposed complete lockdown from 16th May, 2021 [54]. Kerala saw strict lockdown from 8th May, 2021 to handle the second wave [29].

Vaccination in India started from 16th January, 2021. By 10th October, 2021, Number of vaccine doses to the population ratio in West Bengal was 0.64, in Delhi 1.01, in Kerala 1.02, in Maharashtra 0.71 and in Tamil Nadu 0.66 (Fig. 5). Starting from January'21 mid-week till 10th October' $21,68.9 \%$ of the total Indian population got at least first dose of vaccine. Number of vaccine doses to the population ratio was 0.68 . The effectiveness of vaccination combined with lockdown measures imposed in various 
Table 8 Parameter Estimates for Delhi

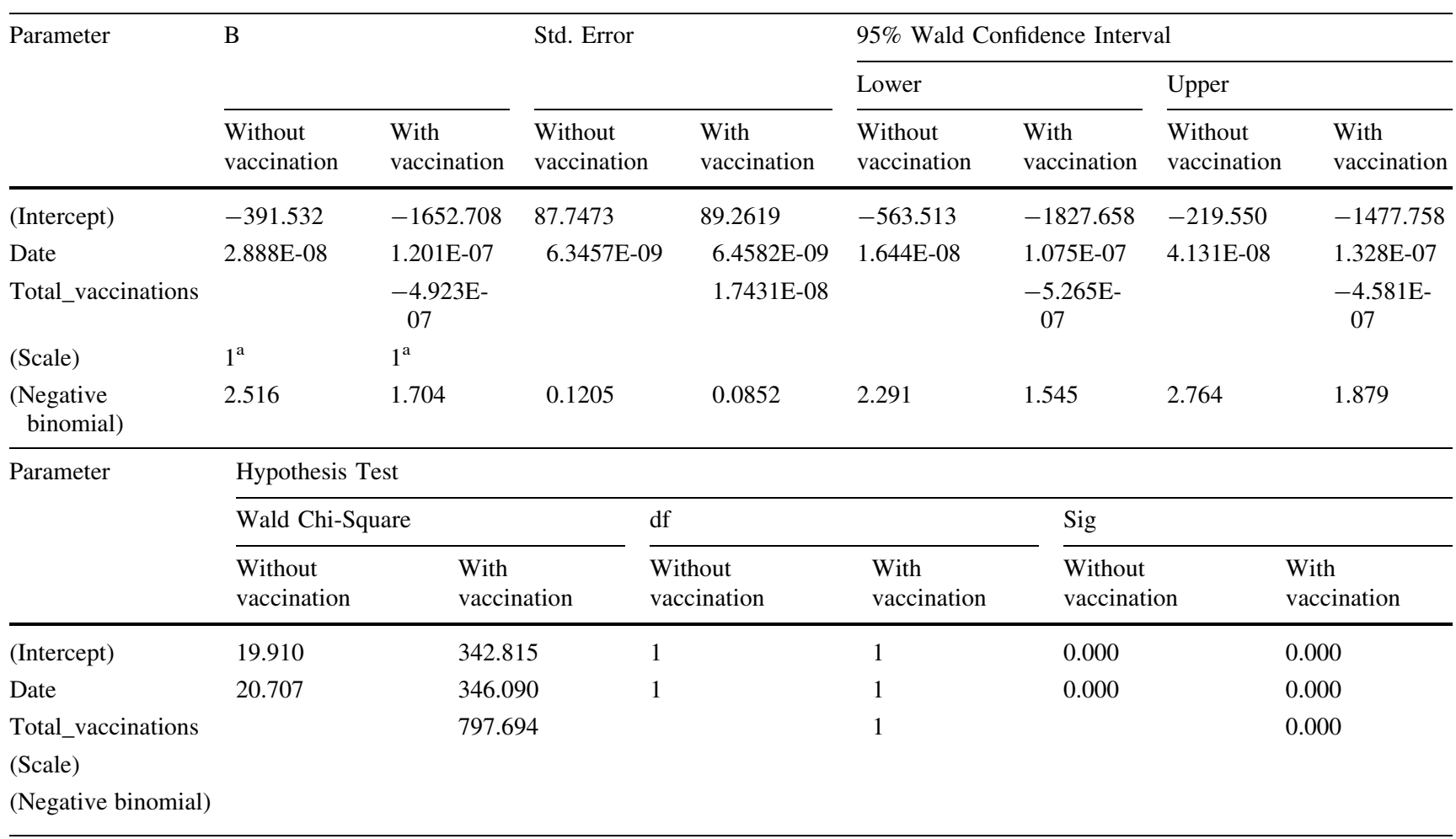

Dependent Variable: Daily_cases

Model: (Intercept), Date (Without vaccination)

Model: (Intercept), Date, Total_vaccinations (With vaccination)

${ }^{a}$ Fixed at the displayed value

individual states can be viewed in the downward trend of daily cases in the prediction model (Fig. 2).

Compared to India, the United States of America faced a more severe form of pandemic. The government-imposed measures such as lockdown, social distancing, and wearing a mask controlled the first wave while subsequent relaxation pushed the nation into second stage with semi-free transmission. Amid the pandemic, last week of May'20, saw a country-wide movement due to racial discrimination issues, with participation of 140 cities in 22 states of USA [58] which might have bolstered the daily confirmed case counts leading to the third wave in USA. Vaccination started from the mid-week of December'20. Number of vaccine doses to the population ratio was 1.21 in USA (till 10th October, 2021) (Fig. 5) indicating complete vaccination of many within the population.

Although USA was worst hit by the pandemic, deaths per million recorded in the United Kingdom were very high. SARS-CoV-2 double mutated variants, $40-80 \%$ more transmissible than wild type variant [20] first identified in UK in November'20 [15, 39, 49] might have been responsible for the second wave. Accumulation of mutations however could not be incorporated within the prediction model, which has perhaps caused the best fitting predictive curve to not completely conform to the actual daily case counts, despite being significant (Fig. 1). Vaccination started from the mid-week of December, 2020 in UK. Number of vaccine doses to the population ratio was 1.39 by $10^{\text {th }}$ October, 2021 (Fig. 5).

Besides UK, Italy also faced a severe form of the pandemic. Stringent lockdown measures were eased after the first wave. In September'20, school reopening was considered "an absolute priority" [25]. Reinstatement of daily activities, crowding in public transport [7] impaired social distancing causing the next surge in October'20. Vaccination program started from the last week of December in Italy. Number of vaccine doses to the population ratio was 1.42 by $10^{\text {th }}$ October, 2021 (Fig. 5). On inclusion of vaccination as a predictor for model development, daily case counts in predictive model were observed to decrease (Fig. 1d). With the predictive curve dropping towards the 
Table 9 Parameter Estimates for Kerala

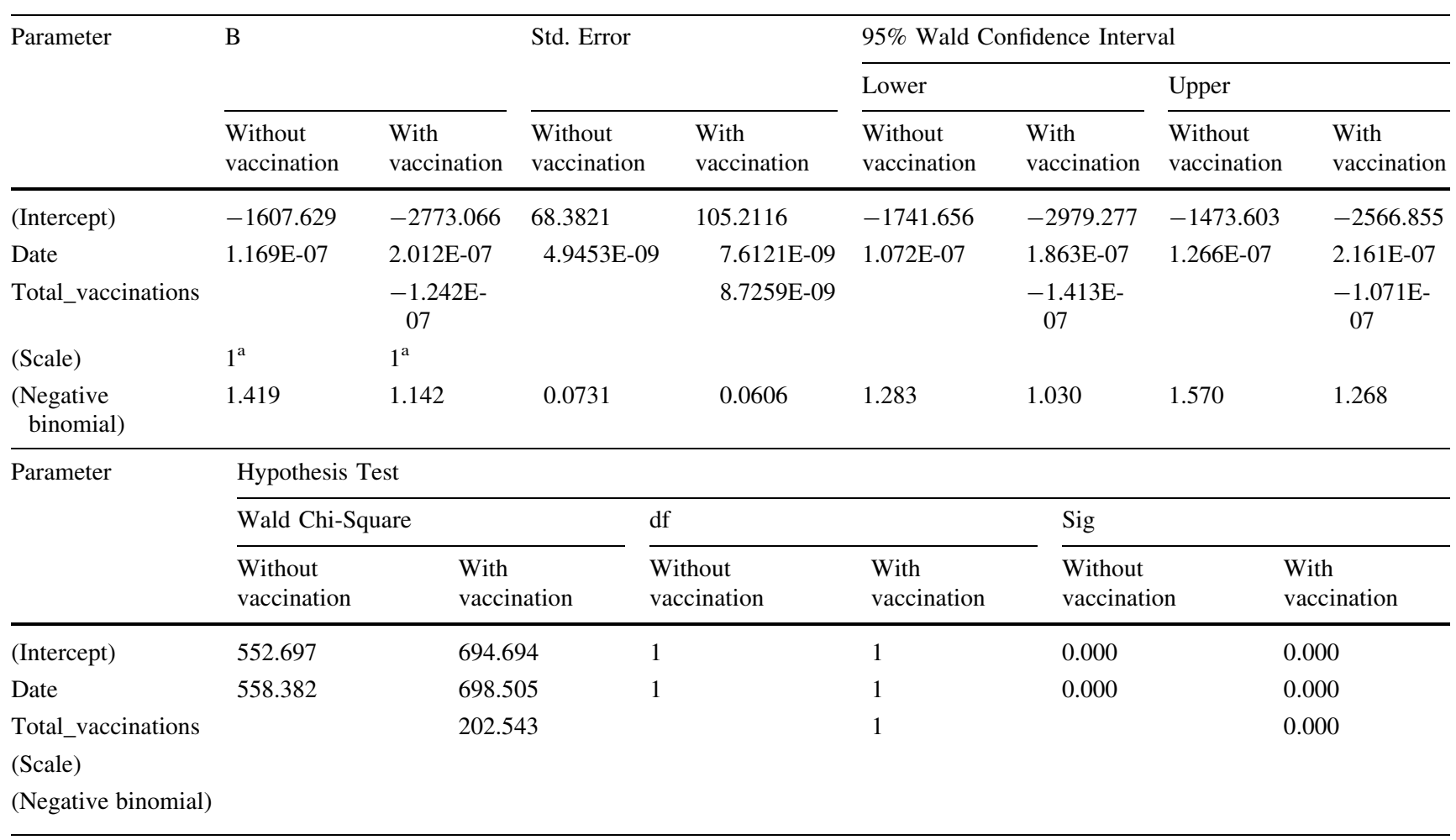

Dependent Variable: Daily_cases

Model: (Intercept), Date (Without vaccination)

Model: (Intercept), Date, Total_vaccinations (With vaccination)

${ }^{\mathrm{a}}$ Fixed at the displayed value

$\mathrm{x}$-axis, vaccination can be held as the primary accountable factor in controlling the pandemic.

Compared to other locations, South Africa faced a less severe form of the pandemic. Strict lockdown policy controlled first wave following which lockdown was relaxed to overcome economic crisis during pandemic [48]. Double mutant strains of SARS-CoV-2 (B.1.351) reported in the month of December'20, were assessed to be more transmissible [6]. On 17th February'21, South Africa started vaccination program. Number of vaccine doses to the population ratio was 0.31 by 10 th October, 2021 (Fig. 5).
Vaccination might have been the key factor in controlling the third wave here.

As vaccination progress, the actual cases decrease, fall the within the upper and lower bounds of $95 \% \mathrm{CI}$ and models become more efficient. Although the estimated daily case counts started showing a downward trend, in some cases, it rose again. Further vaccination, meting double doses to entire population, can effectuate an end to the current situation. 
Table 10 Parameter Estimates for Maharashtra

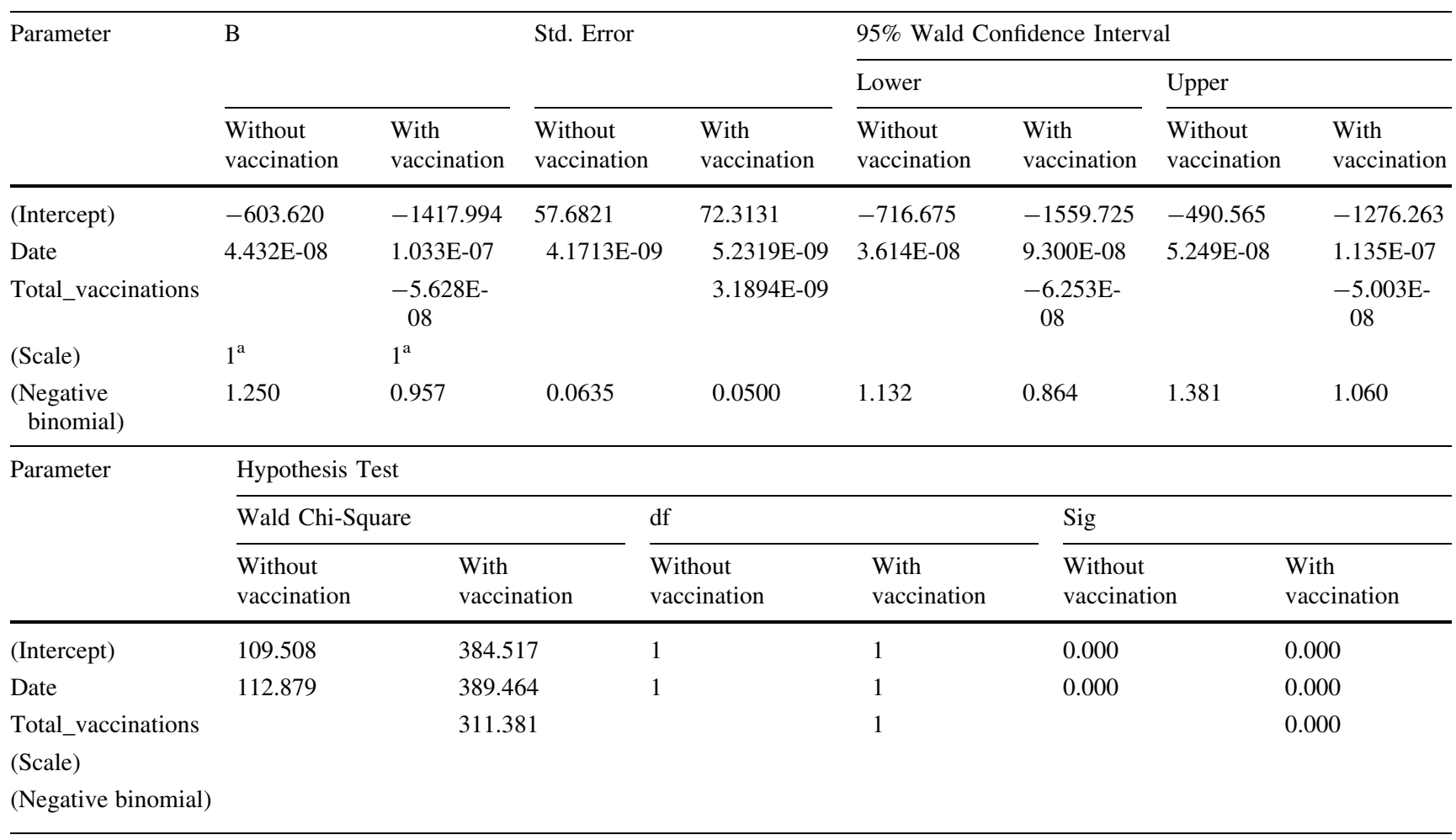

Dependent Variable: Daily_cases

Model: (Intercept), Date (Without vaccination)

Model: (Intercept), Date, Total_vaccinations (With vaccination)

${ }^{a}$ Fixed at the displayed value

\section{Conclusion}

Daily counts of confirmed cases can be successfully predicted based on the prediction models developed in the study. The prediction models were significant and predicted the best fitting confirmed case numbers based on original case counts and vaccination. All the possible causes inflating case counts could not be numerically enunciated which is a major limitation of the study. This might be the reason why the predicted numbers, although significant within $95 \% \mathrm{CI}$, did not completely conform to the original numbers. However, the effect of vaccination can be distinctly visualized in the predicted curves. Vaccination program is effective in controlling COVID-19 pandemic. 
Table 11 Parameter Estimates for Tamil Nadu

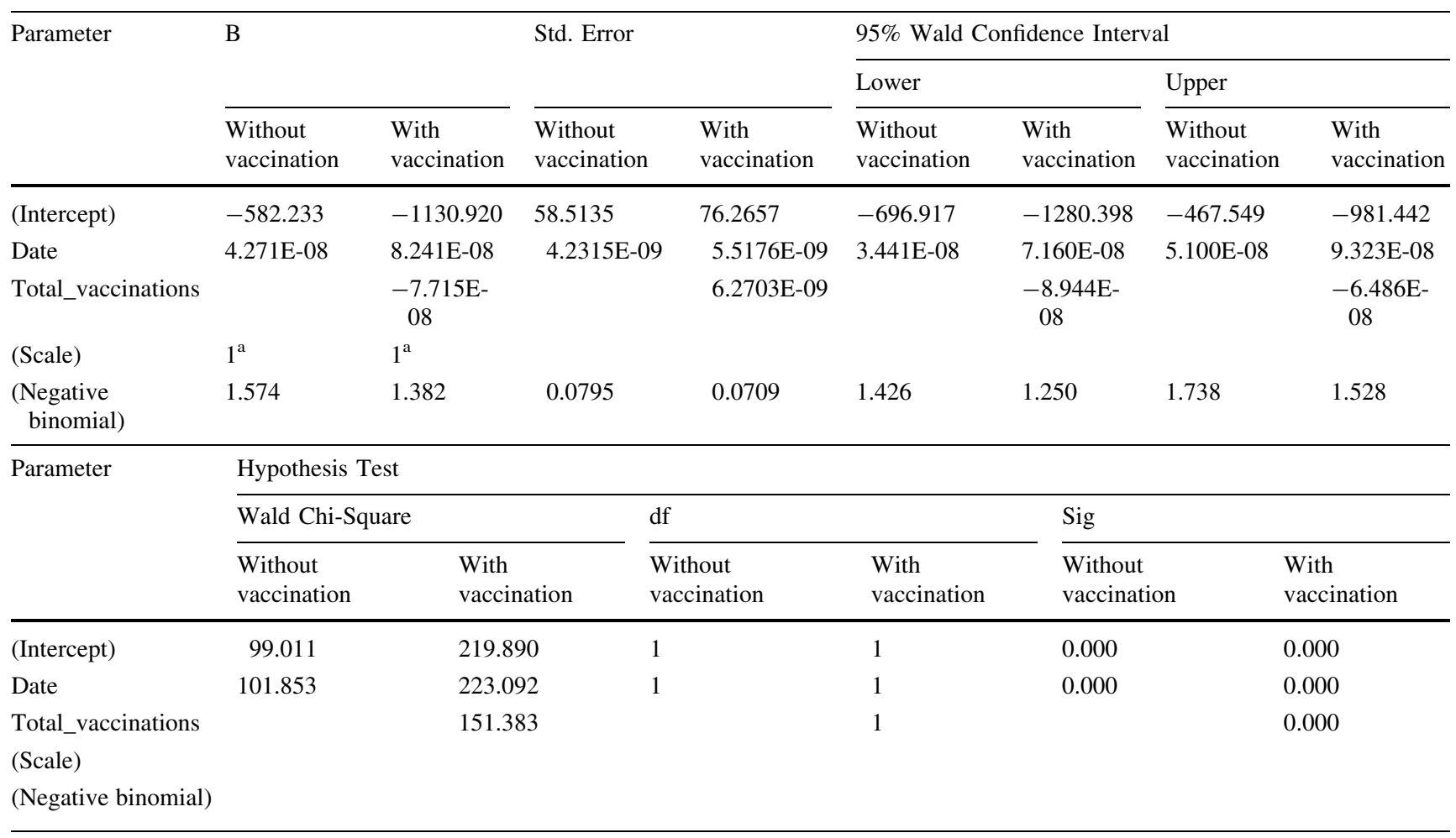

Dependent Variable: Daily_cases

Model: (Intercept), Date (Without vaccination)

Model: (Intercept), Date, Total_vaccinations (With vaccination)

${ }^{a}$ Fixed at the displayed value 

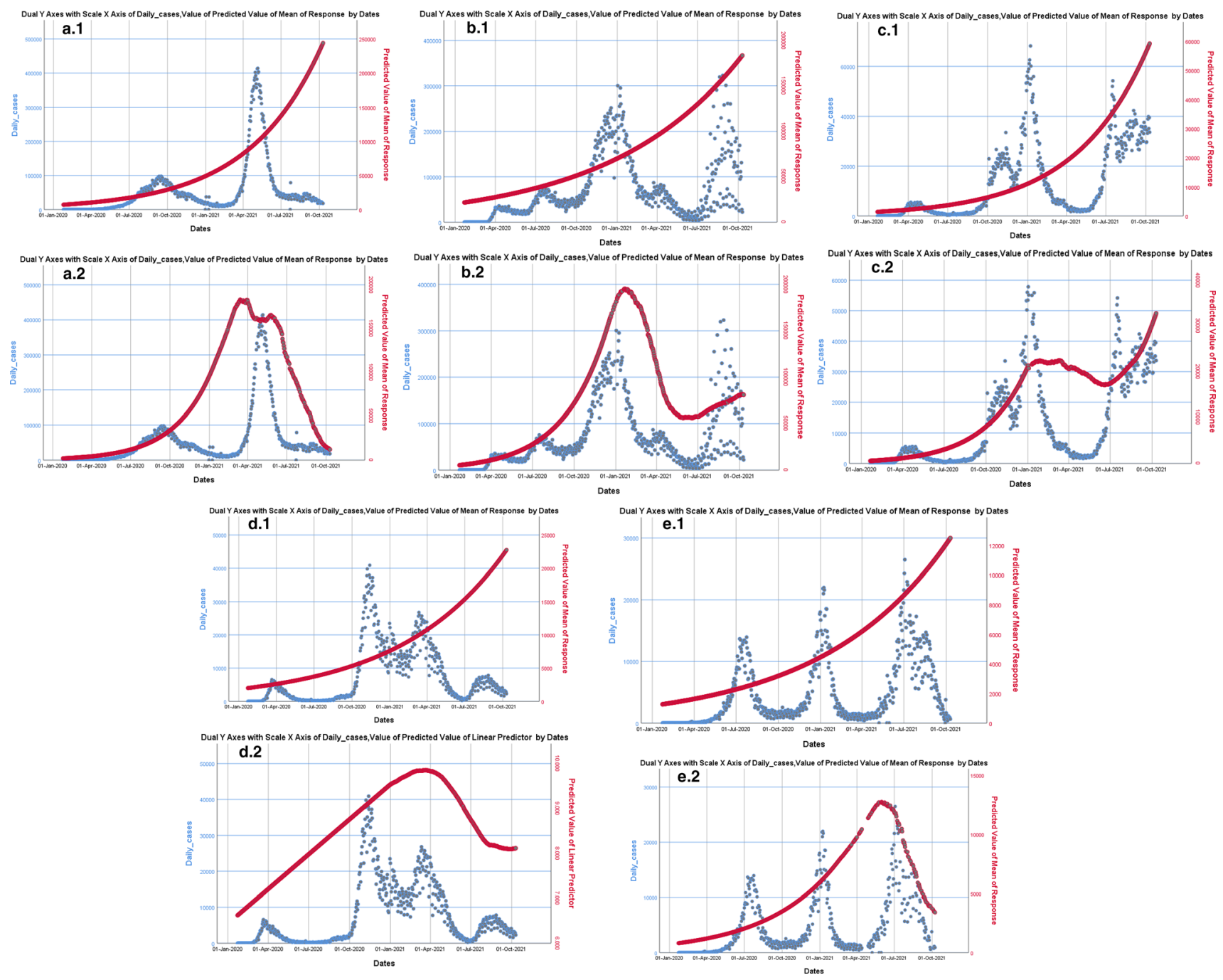

Fig. 1 Daily cases, Value of predicted value of Mean of Response by Date for countries. a.1 Daily cases, Value of predicted value of Mean of Response by Date for India (Blue line- Actual cases, Red linePredicted value) (Without vaccination). a.2 Daily cases, Value of predicted value of Mean of Response by Date for India (Blue lineActual cases, Red line-Predicted value) (With vaccination). b.1 Daily cases, Value of predicted value of Mean of Response by Date for USA (Blue line-Actual cases, Red line- Predicted value) (Without vaccination). b.2 Daily cases, Value of predicted value of Mean of Response by Date for USA (Blue line-Actual cases, Red linePredicted value) (With vaccination). c.1 Daily cases, Value of predicted value of Mean of Response by Date for UK (Blue lineActual cases, Red line- Predicted value) (Without vaccination). c.2

Daily cases, Value of predicted value of Mean of Response by Date for UK (Blue line- Actual cases, Red line-Predicted value) (With vaccination). d.1 Daily cases, Value of predicted value of Mean of Response by Date for Italy (Blue line-Actual cases, Red linePredicted value) (Without vaccination). d.2 Daily cases, Value of predicted value of Mean of Response by Date for Italy (Blue lineActual cases, Red line-Predicted value) (With vaccination). e.1 Daily cases, Value of predicted value of Mean of Response by Date for South Africa (Blue line- Actual cases, Red line- Predicted value) (Without vaccination). e.2 Daily cases, Value of predicted value of Mean of Response by Date for South Africa (Blue line- Actual cases, Red line- Predicted value) (With vaccination) 

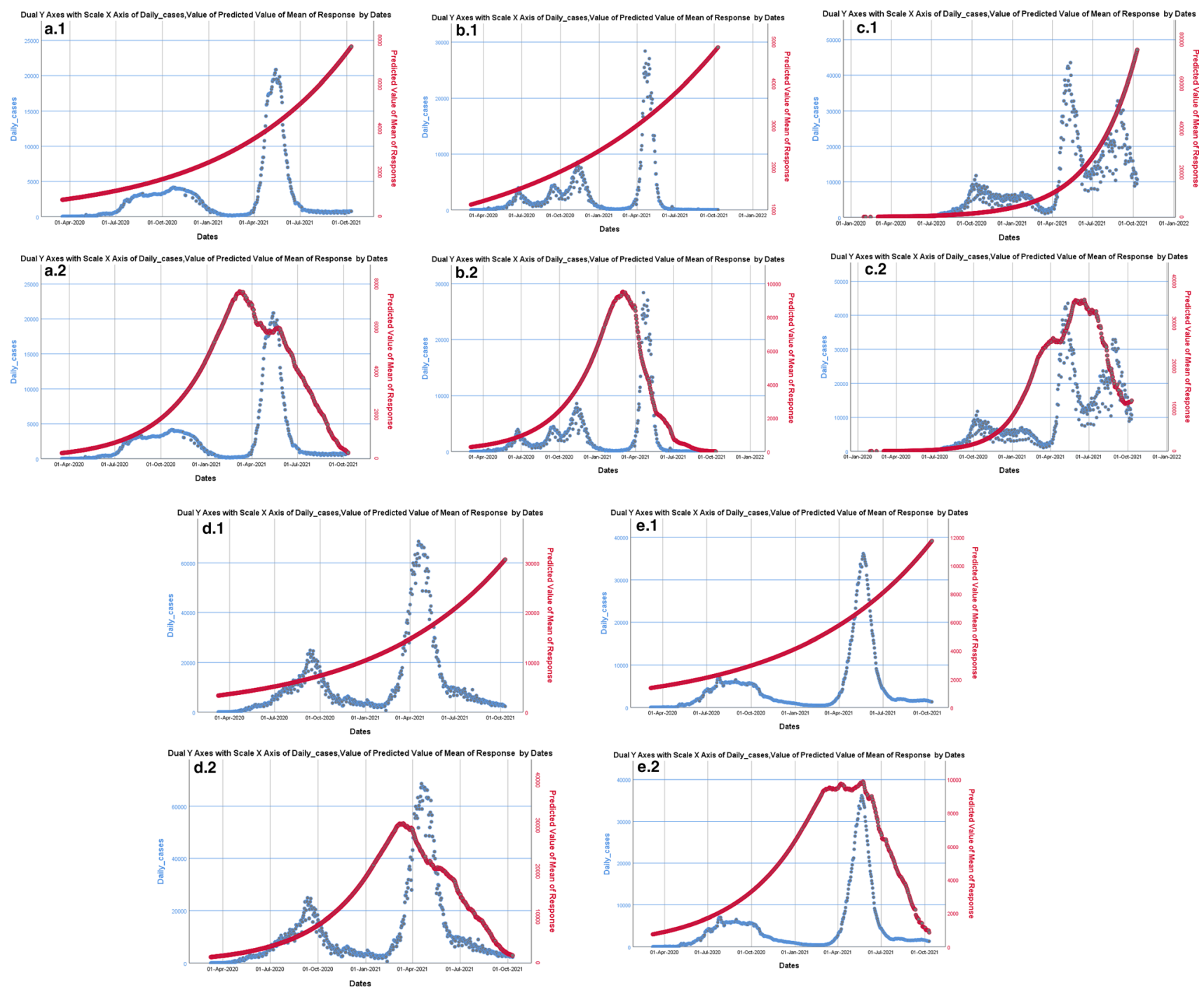

Fig. 2 Daily cases, Value of predicted value of Mean of Response by Date for Indian states. a.1 Daily cases, Value of predicted value of Mean of Response by Date for W. Bengal (Blue line-Actual cases, Red line-Predicted value) (Without vaccination). a.2 Daily cases, Value of predicted value of Mean of Response by Date for W. Bengal (Blue line-Actual cases, Red line- Predicted value) (With vaccination). b.1 Daily cases, Value of predicted value of Mean of Response by Date for Delhi (Blue line- Actual cases, Red line-Predicted value) (Without vaccination). b.2 Daily cases, Value of predicted value of Mean of Response by Date for Delhi (Blue line- Actual cases, Red line- Predicted value) (With vaccination). c.1 Daily cases, Value of predicted value of Mean of Response by Date for Kerala (Blue lineActual cases, Red line- Predicted value) (Without vaccination). c.2

Daily cases, Value of predicted value of Mean of Response by Date for Kerala (Blue line-Actual cases, Red line-Predicted value) (With vaccination). d.1 Daily cases, Value of predicted value of Mean of Response by Date for Maharashtra (Blue line- Actual cases, Red linePredicted value) (Without vaccination). d.2 Daily cases, Value of predicted value of Mean of Response by Date for Maharashtra (Blue line-Actual cases, Red line-Predicted value) (With vaccination). e.1 Daily cases, Value of predicted value of Mean of Response by Date for Tamil Nadu (Blue line-Actual cases, Red line- Predicted value) (Without vaccination). e.2 Daily cases, Value of predicted value of Mean of Response by Date for Tamil Nadu (Blue line-Actual cases, Red line-Predicted value) (With vaccination) 


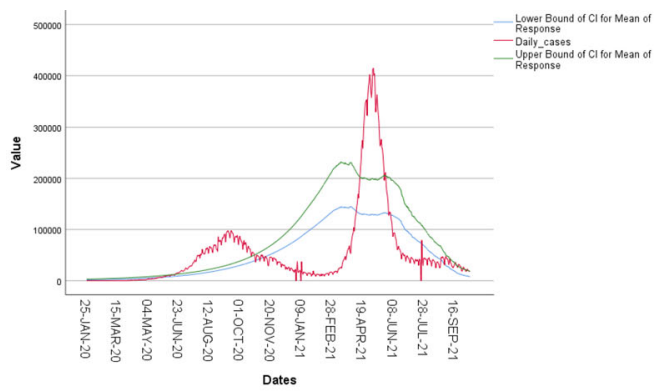

C

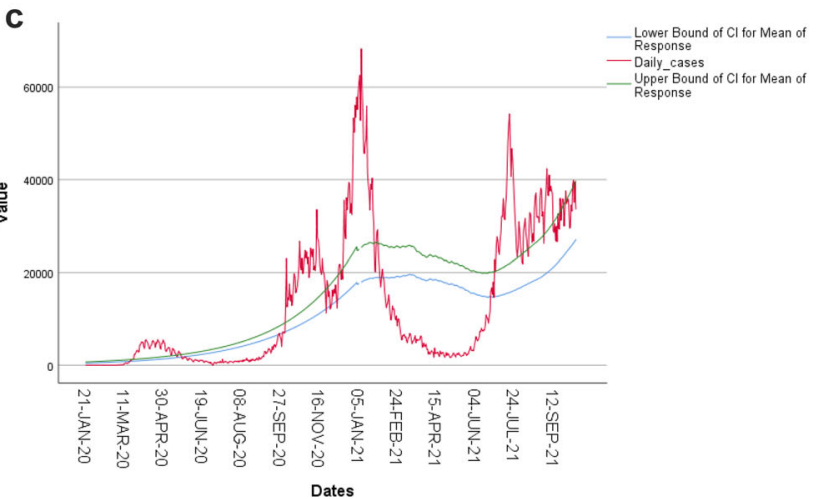

b

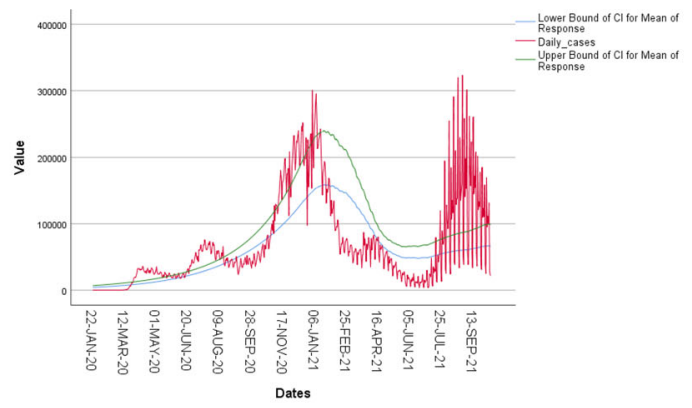

d

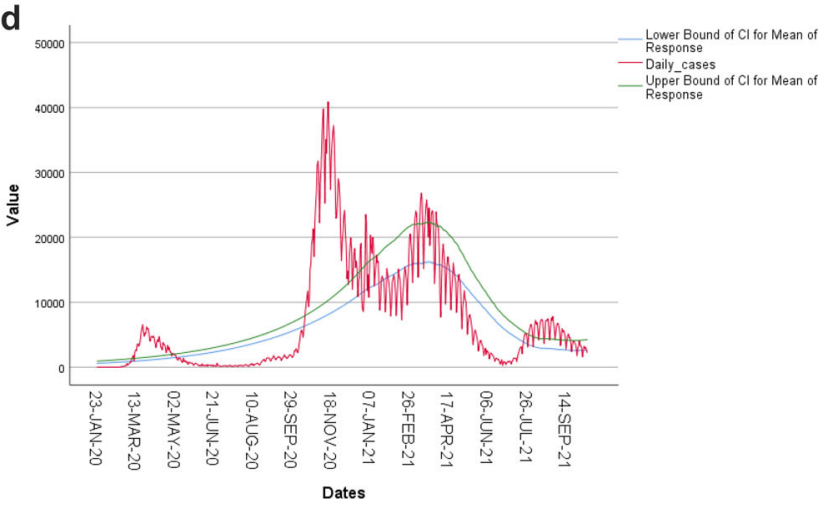

e

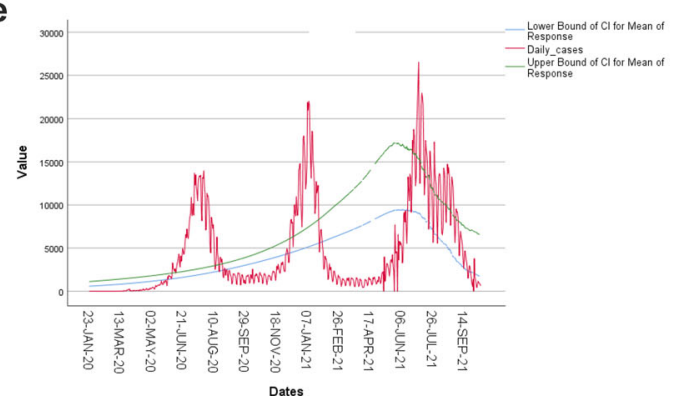

Fig. 3 Actual cases with Lower and upper bound of confidence interval for countries (With vaccination) (green line-upper bound, red line-value for actual cases, blue line upper bound) (3a-India, 3b-USA, 3c-UK, 3d-Italy, 3e-South Africa) 

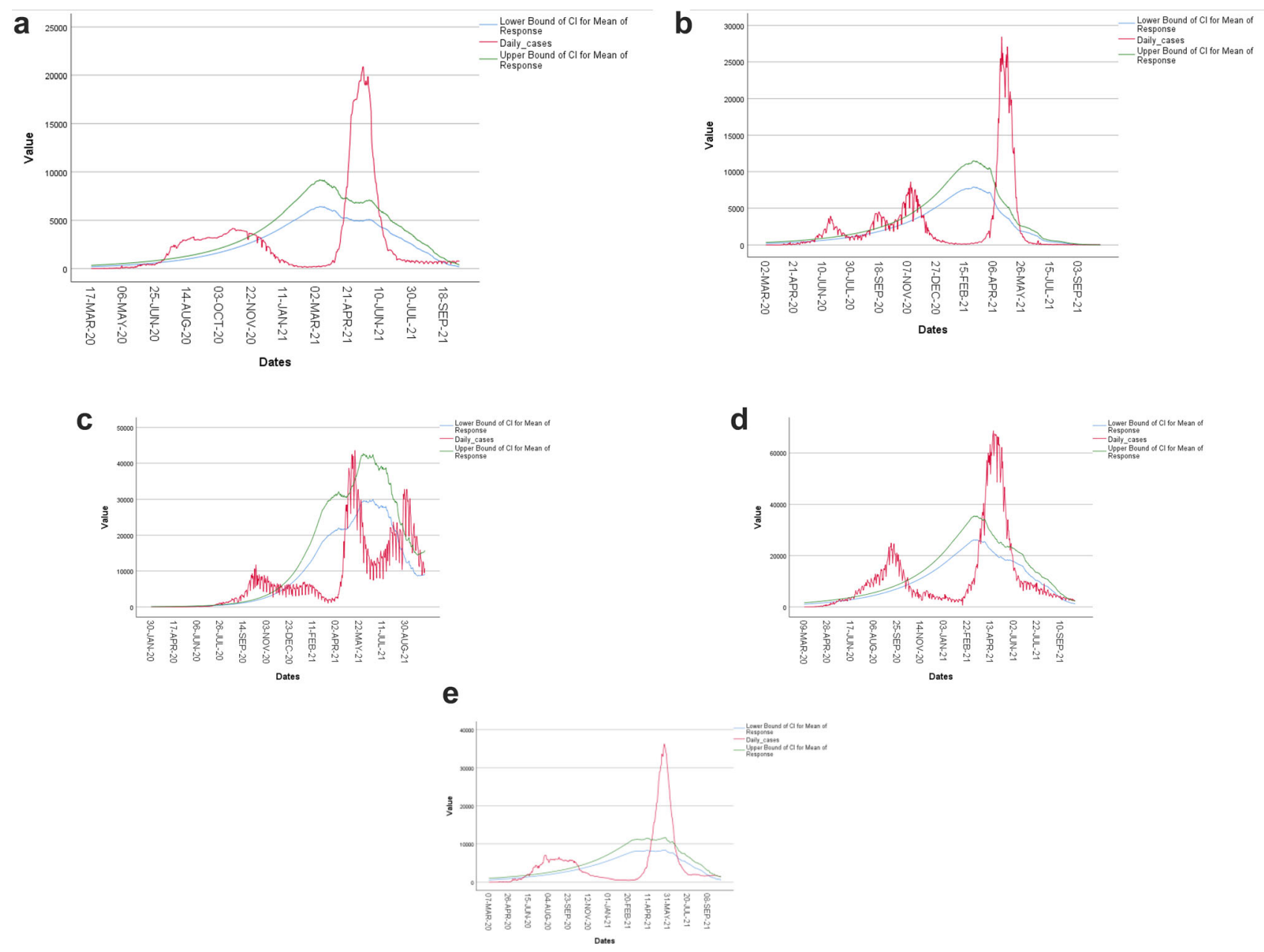

Fig. 4 Actual cases with Lower and upper bound of confidence interval for Indian states (With vaccination) (green line- upper bound, red linevalue for actual cases, blue line upper bound)(4a-West Bengal, 4b-Delhi, 4c-Kerala, 4d-Maharashtra, 4e-Tamil Nadu)

Fig. 5 Number of vaccine doses to the population ratio for countries and States

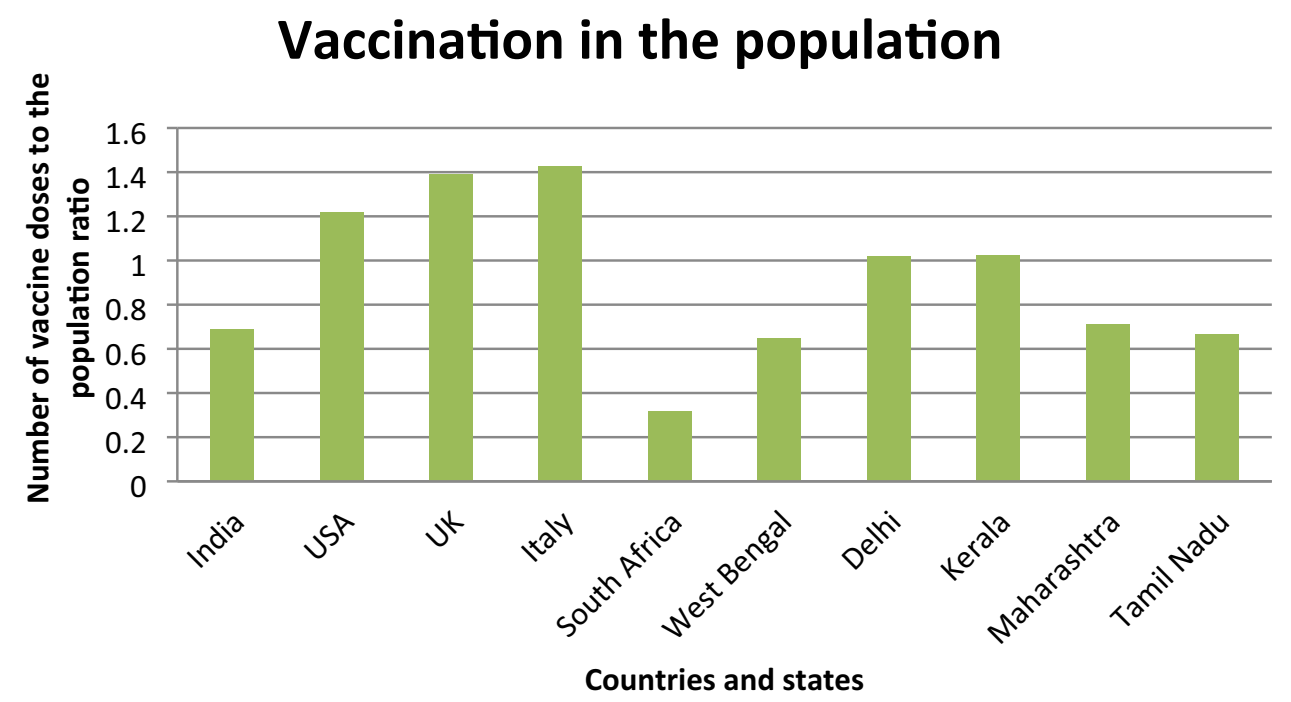


Acknowledgements The authors thank Mr. Chayan Bhattacharya, Ms. Poushalee Dey, Ms. Maitri Singh and Ms. Sulagna Mondal (Department of Life Sciences, Presidency University, Kolkata) for their advice and constant support.

Funding No funding received.

\section{Declarations}

Conflict of interest The authors declare that they have no conflict of interest.

Ethical approval As this study was based on publicly available data on government websites, no ethical approval was required.

\section{References}

1. Andrews MA, Areekal B, Rajesh KR, Krishnan J, Suryakala R, Krishnan B, et al. First confirmed case of COVID-19 infection in India: a case report. Indian J Med Res. 2020;151:490.

2. Araújo MB, Mestre F, Naimi B. Ecological and epidemiological models are both useful for SARS-CoV-2. Nat Ecol Evol. 2020. https://doi.org/10.1038/s41559-020-1246-y.

3. COVID-19: Complete lockdown in Delhi from April 19 midnight till April 26 morning I Delhi News I Zee News [Internet]. [cited 2021 Aug 9]. Available from: https://zeenews.india.com/india/ covid-19-delhi-to-go-under-complete-curfew-from-april-19-mid night-till-april-26-morning-2355889.html

4. COVID-19 Epidemic and Pattern of Global Distribution. J Sci Technol. 2020;5:125-37.

5. COVID Live Update: 203,530,641 Cases and 4,310,044 Deaths from the Coronavirus - Worldometer [Internet]. [cited 2021 Aug 9]. Available from: https://www.worldometers.info/coronavirus/ ?fbclid=IwAR35ZFiRZJ8tyBCwazX2N-k7yJjZOLDQiZSA_MsJ AfdK74s8f2a_Dgx4iVk

6. Chen J, Wang R, Wang M, Wei GW. Mutations strengthened SARS-CoV-2 infectivity. J Mol Biol. 2020;432:5212-26.

7. Chirico F, Sacco A, Nucera G, Magnavita N. Coronavirus disease 2019: the second wave in Italy. J Heal Res. 2021;35:359-63.

8. Complete lockdown in Tamil Nadu for 14 days from May 10: What's open, what's not - Coronavirus Outbreak News [Internet]. [cited 2021 Aug 9]. Available from: https://www.indiatoday.in/ coronavirus-outbreak/story/complete-lockdown-tamil-nadu-14days-may-10-24-covid19-cases-what-is-open-closed-18001372021-05-08

9. Coronavirus: Is the US the worst-hit country for deaths? - BBC News [Internet]. [cited 2021 Aug 9]. Available from: https:// www.bbc.com/news/world-us-canada-53780196

10. Coronavirus: UK could be "worst affected" country in Europe BBC News [Internet]. [cited 2021 Aug 9]. Available from: https://www.bbc.com/news/uk-52261859

11. Coronavirus Update (Live): 133,853,626 Cases and 2,904,358 Deaths from COVID-19 Virus Pandemic - Worldometer [Internet]. [cited 2021 Apr 8]. Available from: https://www.world ometers.info/coronavirus/

12. Coronavirus Outbreak in India - covid19india.org [Internet]. [cited 2021 Aug 9]. Available from: https://www.covid19india. org/

13. Coronavirus I Sarma rules out lockdown in Assam - The Hindu [Internet]. [cited 2021 Jun 23]. Available from: https://www.the hindu.com/news/national/other-states/coronavirus-sarma-rulesout-lockdown-in-assam/article34273071.ece
14. Coronavirus Graphs: Worldwide Cases and Deaths - Worldometer [Internet]. [cited 2021 Sep 24]. Available from: https:// www.worldometers.info/coronavirus/worldwide-graphs/

15. Covid: WHO renames UK and other variants with Greek letters BBC News [Internet]. [cited 2021 Aug 9]. Available from: https://www.bbc.com/news/world-57308592

16. Cyclone Yaas: Severe storm lashes India and Bangladesh - BBC News [Internet]. [cited 2021 Jun 23]. Available from: https:// www.bbc.com/news/world-asia-india-57237953

17. Cyclone Tauktae: Seventy-seven missing at sea in the wake of storm - BBC News [Internet]. [cited 2021 Jun 23]. Available from: https://www.bbc.com/news/uk-57139989

18. Cyranoski D. 'We need to be alert': Scientists fear second coronavirus wave as China's lockdowns ease. Nature. Springer Science and Business Media LLC; 2020.

19. Dai L, Gao GF. Viral targets for vaccines against COVID-19. Nat Rev Immunol 2020212 [Internet]. Nature Publishing Group; 2020 [cited 2021 Aug 9];21:73-82. Available from: https://www. nature.com/articles/s41577-020-00480-0

20. Davies NG, Abbott S, Barnard RC, Jarvis CI, Kucharski AJ, Munday JD, et al. Estimated transmissibility and impact of SARS-CoV-2 lineage B.1.1.7 in England. Science. 2021. https:// doi.org/10.1126/science.abg3055.

21. Double COVID-19 mutant strain found in Maharashtra, Bengal, Delhi, 7 other states [Internet]. [cited 2021 Jun 16]. Available from: https://www.businesstoday.in/latest/trends/double-covid19-mutant-strain-found-in-maharashtra-bengal-delhi-7-other-stat es/story/436746.html

22. Ghosh P, Ghosh R, Chakraborty B. COVID-19 in India: Statewise Analysis and Prediction. JMIR Public Heal Surveill [Internet]. JMIR Publications Inc.; 2020 [cited 2021 Aug 26];6. Available from: /pmc/articles/PMC7431238/.

23. Herd immunity unviable, Covid-19 vaccine the only solution I Health - Hindustan Times [Internet]. [cited 2021 Aug 9]. Available from: https://www.hindustantimes.com/health/herd-immu nity-unviable-covid-19-vaccine-the-only-solution/story-0scIr6 O3nERUQgMrfl5mhJ.html

24. India's first coronavirus infection confirmed in Kerala - The Hindu [Internet]. [cited 2021 Aug 9]. Available from: https:// www.thehindu.com/news/national/indias-first-coronavirus-infec tion-confirmed-in-kerala/article30691004.ece

25. Italy warned schools "must reopen at any cost" despite new coronavirus outbreaks - The Local [Internet]. [cited 2021 Aug 9]. Available from: https://www.thelocal.it/20200817/italy-warnsschools-must-reopen-at-any-cost-despite-new-coronavirus-out breaks/

26. Italy overtakes UK for worst coronavirus death toll in Europe I South China Morning Post [Internet]. [cited 2021 Aug 9]. Available from: https://www.scmp.com/news/world/europe/arti cle/3113839/italy-overtakes-uk-worst-coronavirus-death-tolleurope

27. Kaplan RM, Milstein A. Influence of a COVID-19 vaccine's effectiveness and safety profile on vaccination acceptance. Proc Natl Acad Sci. 2021;118:2021726118.

28. Kar SK, Ransing R, Arafat SMY, Menon V. Second wave of COVID-19 pandemic in India: barriers to effective governmental response. EClin Med. 2021;36:100915.

29. Kerala announces complete lockdown from May 8 to May 16 over Covid surge - Coronavirus Outbreak News [Internet]. [cited 2021 Aug 9]. Available from: https://www.indiatoday.in/cor onavirus-outbreak/story/kerala-announces-complete-lockdownfrom-till-may-16-over-covid-1799421-2021-05-06

30. Kim L, Whitaker M, O’Halloran A, Kambhampati A, Chai SJ, Reingold A, et al. Hospitalization Rates and Characteristics of Children Aged $<18$ Years Hospitalized with Laboratory-Confirmed COVID-19 - COVID-NET, 14 States, March 1-July 25, 
2020. MMWR Morb Mortal Wkly Rep [Internet]. Centers for Disease Control MMWR Office; 2020 [cited 2021 Feb 9];69:1081-8. Available from: /pmc/articles/PMC7440125/.

31. Kumbh Mela and election rallies: How two super spreader events have contributed to India's massive second wave of COVID-19 cases-India News, Firstpost [Internet]. [cited 2021 Jun 23]. Available from: https://www.firstpost.com/india/kumbh-melaand-election-rallies-how-two-super-spreader-events-have-contrib uted-to-indias-massive-second-wave-of-covid-19-cases-9539551. html

32. Lake MA. What we know so far: COVID-19 current clinical knowledge and research [Internet]. Clin. Med. J. R. Coll. Physicians London. Royal College of Physicians; 2020 [cited $2021 \mathrm{Feb}$ 13]. p. 124-7. Available from: https://pubmed.ncbi.nlm.nih.gov/ 32139372/

33. Liu Y, Gu Z, Xia S, Shi B, Zhou X-N, Shi Y, et al. What are the underlying transmission patterns of COVID-19 outbreak? An age-specific social contact characterization. EClinicalMedicine [Internet]. Elsevier; 2020 [cited 2021 Aug 9];22:100354. Available from: /pmc/articles/PMC7165295/.

34. Liu Y, Gu Z, Xia S, Shi B, Zhou XN, Shi Y, et al. What are the underlying transmission patterns of COVID-19 outbreak? An age-specific social contact characterization. EClinicalMedicine [Internet]. Lancet Publishing Group; 2020 [cited 2021 Jun 21];22. Available from: /pmc/articles/PMC7165295/.

35. Maharashtra imposes weekend lockdown, night curfew as Covid grip tightens I All you need to know - Coronavirus Outbreak News [Internet]. [cited 2021 Aug 9]. Available from: https:// www.indiatoday.in/coronavirus-outbreak/story/maharashtra-imp oses-weekend-lockdown-night-curfew-as-covid-grip-tightens-allyou-need-to-know-1787098-2021-04-04

36. Mathieu E, Ritchie H, Ortiz-Ospina E, Roser M, Hasell J, Appel C, et al. A global database of COVID-19 vaccinations. Nat Hum Behav. Nature Research; 2021.

37. Mecenas P, Bastos RT da RM, Vallinoto ACR, Normando D. Effects of temperature and humidity on the spread of COVID-19: A systematic review. Samy AM, editor. PLoS One [Internet]. Public Library of Science; 2020 [cited 2021 Feb 17];15:e0238339. Available from: https://dx.plos.org/https://doi. org/10.1371/journal.pone.0238339

38. Meo SA, Abukhalaf AA, Alomar AA, AlMutairi FJ, Usmani AM, Klonoff DC. Impact of lockdown on COVID-19 prevalence and mortality during 2020 pandemic: observational analysis of 27 countries. Eur J Med Res. 2020. https://doi.org/10.1186/s40001020-00456-9.

39. New research: UK variant of Covid-19 transmits faster, but no evidence symptoms are worse I Explained News, The Indian Express [Internet]. [cited 2021 Aug 9]. Available from: https:// indianexpress.com/article/explained/uk-variant-of-covid-19-trans mission-symptoms-7272761/

40. Ranjan R, Sharma A, Mahendra, Verma K, Verma MK. Characterization of the Second Wave of COVID-19 in India. medRxiv [Internet]. Cold Spring Harbor Laboratory Press; 2021 [cited 2021 Jun 16];2021.04.17.21255665. Available from: https://doi. org/10.1101/2021.04.17.21255665

41. Rath RS, Dixit AM, Koparkar AR, Kharya P, Joshi HS. COVID19 pandemic in India: a comparison of pandemic pattern in Selected States. Nepal J Epidemiol. 2020;10:856.

42. Rodríguez-Hidalgo AJ, Pantaleón Y, Dios I, Falla D. Fear of COVID-19, Stress, and Anxiety in University Undergraduate Students: A Predictive Model for Depression. Front Psychol. Frontiers; 2020;0:3041.

43. Rothan HA, Byrareddy SN. The epidemiology and pathogenesis of coronavirus disease (COVID-19) outbreak [Internet]. J. Autoimmun. Academic Press; 2020 [cited 2021 Feb 13]. Available from: https://pubmed.ncbi.nlm.nih.gov/32113704/
44. Shen C, Wang Z, Zhao F, Yang Y, Li J, Yuan J, et al. Treatment of critically Ill patients with COVID-19 with convalescent plasma. JAMA. 2020;323:1582-9.

45. Sobral MFF, Duarte GB, da Penha Sobral AIG, Marinho MLM, de Souza MA. Association between climate variables and global transmission oF SARS-CoV-2. Sci Total Environ. 2020;729:138997.

46. Social Distancing Coronavirus (COVID 19) Outbreak: The Rules of Social Distancing I What is Social Distancing covid 19 [Internet]. [cited 2021 Jun 23]. Available from: https://time sofindia.indiatimes.com/life-style/health-fitness/health-news/coro navirus-outbreak-the-rules-of-social-distancing/articleshow/7465 0718.cms

47. South Africa - People - Ethnic Groups [Internet]. [cited 2021 Aug 9]. Available from: https://www.jyu.fi/viesti/verkkotuotanto/kp/ sa/peop_ethnicgrps.shtml

48. Stiegler N, Bouchard J-P. South Africa: challenges and successes of the COVID-19 lockdown. Ann Med Psychol. 2020;178:695.

49. U.K. becomes alpha and South Africa beta as WHO identifies SARS-CoV-2 variants by Greek letters rather than country of origin - MarketWatch [Internet]. [cited 2021 Aug 9]. Available from: https://www.marketwatch.com/story/u-k-becomes-alphaand-south-africa-beta-as-who-identifies-sars-cov-2-variants-bygreek-letters-rather-than-country-of-origin-01622634376

50. UK variant, African virus strain detected in Kerala, says CM Pinarayi Vijayan I Latest News India - Hindustan Times [Internet]. [cited 2021 Jun 16]. Available from: https://www.hindus tantimes.com/india-news/uk-variant-african-virus-strain-detec ted-in-kerala-says-cm-pinarayi-vijayan-101619461098976.html

51. Vaccination is the only long-term solution to COVID-19 crisis in India, says Fauci - The Hindu [Internet]. [cited 2021 Aug 9]. Available from: https://www.thehindu.com/news/national/vacci nation-is-the-only-long-term-solution-to-covid-19-crisis-in-indiasays-fauci/article34522378.ece

52. Velavan TP, Meyer CG. The COVID-19 epidemic [Internet]. Trop. Med. Int. Heal. Blackwell Publishing Ltd; 2020 [cited 2021 Feb 13]. p. 278-80. Available from: https://pubmed.ncbi.nlm.nih. gov/32052514/

53. Vinciguerra M, Greco E. Sars-CoV-2 and black population: ACE2 as shield or blade? Infect Genet Evol. 2020;84:104361.

54. West Bengal announces complete lockdown from May 16-30 to curb Covid-19 spread- The New Indian Express [Internet]. [cited 2021 Aug 9]. Available from: https://www.newindianexpress. com/nation/2021/may/15/west-bengal-govt-announces-completelockdown-from-may-16-30-to-curb-covid-19-spread-2302880. html

55. Wu D, Wu T, Liu Q, Yang Z. The SARS-CoV-2 outbreak: What we know [Internet]. Int. J. Infect. Dis. Elsevier B.V.; 2020 [cited $2021 \mathrm{Feb}$ 13]. p. 44-8. Available from: https://pubmed.ncbi.nlm. nih.gov/32171952/

56. Young KP, Kolcz DL, O'Sullivan DM, Ferrand J, Fried J, Robinson K. Health care workers' mental health and quality of life during COVID-19: results from a mid-pandemic, national survey. Psychiatr Serv Am Psychiatric Assoc. 2021;72:122-8.

57. Zhao H, Merchant NN, McNulty A, Radcliff TA, Cote MJ, Fischer RSB, et al. COVID-19: Short term prediction model using daily incidence data. PLoS ONE. 2021. https://doi.org/10.1371/ journal.pone.0250110.

58. Zheng Z, Xie Z, Qin Y, Wang K, Yu Y, Fu P. Exploring the influence of human mobility factors and spread prediction on early COVID-19 in the USA. BMC Publ Health. 2021;21:1-13.

Publisher's Note Springer Nature remains neutral with regard to jurisdictional claims in published maps and institutional affiliations. 